Fearnley, Gareth W., Latham, Antony M.,

Hollstein, Monica, Odell, Adam ORCID: https://orcid.org/0000-00026855-7214 and Ponnambalam, Sreenivasan ORCID: https://orcid.org/0000-0002-4452-7619 (2020) ATF-2 and Tpl2 regulation of endothelial cell cycle progression and apoptosis. Cellular Signalling, 66.

Downloaded from: http://ray.yorksj.ac.uk/id/eprint/4216/

The version presented here may differ from the published version or version of record. If you intend to cite from the work you are advised to consult the publisher's version: http://dx.doi.org/10.1016/j.cellsig.2019.109481

Research at York St John (RaY) is an institutional repository. It supports the principles of open access by making the research outputs of the University available in digital form. Copyright of the items stored in RaY reside with the authors and/or other copyright owners. Users may access full text items free of charge, and may download a copy for private study or non-commercial research. For further reuse terms, see licence terms governing individual outputs. Institutional Repository Policy Statement

\title{
RaY
}

Research at the University of York St John

For more information please contact RaY at ray@yorksj.ac.uk 


\section{ATF-2 and Tpl2 regulation of endothelial cell cycle progression and apoptosis}

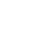

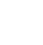
Gareth W. Fearnley ${ }^{1}$, Antony M. Latham ${ }^{1}$, Monica Hollstein², Adam F.

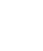
Odell $^{3,4}$, Sreenivasan Ponnambalam ${ }^{1 *}$

${ }^{1}$ School of Molecular \& Cellular Biology, University of Leeds, UK;

${ }^{2}$ Faculty of Medicine \& Health, University of Leeds, UK;

${ }^{3}$ Leeds Institute of Medical Research at St James's, University of Leeds, UK;

${ }^{4}$ School of Health Sciences, York St. John University, Lord Mayor's Walk, York, UK.

Author for correspondence:

Dr Sreenivasan Ponnambalam

Endothelial Cell Biology Unit

School of Molecular \& Cellular Biology

University of Leeds

Leeds LS2 9JT, UK.

Email: s.ponnambalam@leeds.ac.uk 


\section{ABSTRACT}

Cells respond to soluble and membrane-bound factors to activate signalling cascades that control cell proliferation and cell death. Vascular endothelial growth factor A (VEGF-A) is a soluble ligand that modulates a variety of cellular responses including cell proliferation and apoptosis. It is not well understood how VEGF-A signalling pathways regulate cell proliferation and cell death. To address this, we examined VEGF-A-regulated signalling pathways in the cytosol and nucleus and functional requirement for such cellular responses. The VEGF-A-regulated transcription factor, ATF-2, is required for cell cycle proteins such as p53, p21 and Cyclin D1. A cytosolic serine/threonine protein kinase (Tpl2) modulates ATF-2-regulated effects on the endothelial cell cycle. Such regulatory effects impact on endothelial cell proliferation, cell viability and apoptosis. These cellular effects influence complex cell-based organisation such as endothelial tubulogenesis. Our study now provides a framework for incorporating VEGF-A-stimulated signalling events from the cytosol to the nucleus which helps to understand how cell proliferation and apoptosis are controlled.

(158 words)

Keywords: Signal transduction, Cell proliferation, Apoptosis, ATF-2, p53, Tpl2 


\section{Introduction}

Eukaryote organisms sense changes in the extracellular environment and modulate signal transduction pathways that control different aspects of cell physiology and animal function. An important feature of cellular physiology is to tightly regulate cell proliferation and programmed cell death (apoptosis). One question is how membrane receptors bind extracellular ligands and trigger such signalling pathways that modulate cell proliferation and apoptosis [1]. In higher eukaryotes, a wide variety of membrane receptors exist with ubiquitous and tissue-specific regulatory functions. One such class of proteins are the receptor tyrosine kinase (RTK) family which bind extracellular ligands and transduce signals into the cellular interior, thus modulating cell behaviour and function [2, 3]. It is well known that the RTK activation modulates cell cycle progression in a wide variety of cells and tissues. RTKs are thus useful models to better understand how complex eukaryotes integrate signalling pathways with cell cycle progression and apoptosis.

The vascular endothelial growth factor receptor (VEGF) family binds to a subset of receptor tyrosine kinases (VEGFRs) and have provided valuable insights into vascular physiology in health and disease states [4, 5]. The founding member of the VEGF family (i.e. VEGF-A) binds to the pro-angiogenic receptor, VEGFR2, to regulate many aspects of endothelial function including cell migration, proliferation and angiogenesis [6]. The role of VEGF-A and VEGFR2 in promoting signal transduction which impacts on cell migration and endothelial tubule formation (tubulogenesis) is well-characterised. However, the effect of VEGF-A on endothelial cell proliferation although clear-cut, is relatively mild. Interestingly, VEGF-A regulates both cell cycle progression and metabolic control, indicating an ability to simultaneously modulate different biochemical pathways [7].

To answer how VEGF-A regulates biochemical events that contributes to choices between cell proliferation and apoptosis, we examined the functional 
77 roles of components of signalling pathways regulated by VEGF-A. Different 78 studies have identified both cytosolic and nuclear proteins that regulate VEGF79 A-stimulated signal transduction, metabolism and gene expression [6, 8]. We 80 focused on the link between the proto-oncogene and serine/threonine protein 81 kinase, Tpl2 (MAP3K8), the tumour suppressor and cell cycle regulator, p53, 82 and the nuclear transcription factor, ATF-2. Our findings in this study link Tpl283 regulated signal transduction impacting on ATF-2 and p53 levels to regulate 84 cell proliferation and apoptosis which impacts on endothelial tubulogenesis. 


\section{Materials and Methods}

\subsection{Materials}

Antibodies used in this study are goat anti-VEGFR2 (R\&D Systems, Minneapolis, USA), mouse anti-Cyclin D1 (DCS6), mouse anti-p21, rabbit antiATF-2, rabbit anti-phospho-ATF-2 (pT71), rabbit anti-cleaved and total caspase 3, rabbit anti-phospho-VEGFR2-Y1175 (pY1175) (Cell Signaling Technology, Danvers, USA), mouse anti-p53, mouse anti-Cyclin A2, mouse anti-Bax, mouse anti-Cyclin B (BD Transduction Laboratories, Oxford, UK), mouse anti- $\alpha$-tubulin, mouse anti-actin (Sigma-Aldrich, Poole, UK). Endothelial cell growth medium (ECGM) and recombinant human VEGF-A 165 and VEGF$A_{121}$ were from PromoCell (Heidelberg, Germany).

\subsection{Immunoblotting and analysis}

Human umbilical vein endothelial cells (HUVECs) were cultured and grown as previously described [9]. Cells were seeded into 6-well plates until $\sim 80 \%$ confluent, cells were washed twice with PBS and starved overnight in MCDB131 + 0.2\% (w/v) BSA and $2 \mathrm{mM}$ thymidine, to stimulate cell cycle arrest (G1/S). Starvation media was aspirated and cells stimulated in ECGM $+25 \mu \mathrm{M}$ 2-deoxycytidine, containing (0.25 nM) VEGF-A ${ }_{165}$ or VEGF-A 121 if required. Cells were then lysed and processed for immunoblot analysis as previously described [10]. Membranes were imaged using a G:BOX XT4 Chemi imaging system (Syngene, Cambridge, UK). Band intensity was determined using 2-D densitometry running on dedicated image analysis software (Syngene).

\subsection{Quantitative real-time PCR analysis}

HUVECs were subjected to control or ATF-specific siRNA duplex treatments as previously described. Cells were then starved for $2 \mathrm{~h}$ in minimal 
112 media, before stimulation with VEGF-A ( $25 \mathrm{ng} / \mathrm{ml})$ for $2 \mathrm{~h}$ followed by cell lysis and processing for qRT-PCR analysis. Total cellular RNA was reverse transcribed into cDNA using random hexamer primers included in the HighCapacity cDNA Archive Kit (Life Technologies) [11]. PCR reactions were performed in a LightCycler apparatus using the LC-FastStart DNA Master SYBR Green I kit (Roche Diagnostics, Mannheim, Germany) as described previously [12]. $2 \mu \mathrm{g}$ of total RNA were used for first-strand cDNA synthesis with Superscript II reverse transcriptase and oligo d(T)12-18 primers according to the manufacturer's protocol (Life Technologies). Primer sequences used for qRT-PCR are: human Tpl2 forward primer: 5'- CGC AAG AGG CTG AGT A-3' and human Tpl2 reverse primer: 5'-TTC CTG TGC ACG AAG AAT CA-3'. All PCR reactions were optimised at the same annealing temperature of $60^{\circ} \mathrm{C}$ and thermocycling for each reaction was subsequently performed in a final volume of $20 \mu$ containing $2 \mu \mathrm{l}$ of cDNA sample, $4 \mathrm{mM} \mathrm{MgCl}, 0.5 \mu \mathrm{M}$ of each primer and $2 \mu \mathrm{l}$ of LC-FastStart DNA Master SYBR Green I. Samples were initially denatured for $8 \mathrm{~min}$ at $95^{\circ} \mathrm{C}$, followed by 45 cycles of denaturation $\left(95^{\circ} \mathrm{C}\right.$ for $15 \mathrm{sec})$, annealing $\left(60^{\circ} \mathrm{C}\right.$ for $\left.5 \mathrm{sec}\right)$, elongation $\left(72^{\circ} \mathrm{C}\right.$ for $\left.10 \mathrm{sec}\right)$, and a short temperature increase to $82^{\circ} \mathrm{C}$ for $3 \mathrm{sec}$ (for fluorescence measurements). PCR products were quantified relative to a housekeeping gene encoding $\beta$-actin. Expression levels of all other genes are given relative to the expression levels of $\beta$-actin by evaluation of their crossing-over points of product accumulation curves relative to the standard curve of $\beta$-actin. All PCR products were checked by melting point analysis and by agarose gel electrophoresis to verify that products were of correct length.

\subsection{FUCCI immunofluorescence analysis}

The fluorescent ubiquitinated cell cycle indicator (FUCCI) has been previously described [13]. Briefly, a novel puromycin-resistant single co- 
expression construct was generated as follows. Plasmid pLV-eGFP (Addgene \#36083; a gift from Pantelis Tsoulfas) was digested with BamHI and Sall to remove the eGFP open reading frame. PCR primers were used to amplify sequences encoding mKO2-hCdt1 (30/120) (5'-TAG AAG ACA CCG ACT CTA GAG GAT CCA TGG TGA GTG TGA TTA AAC-3' and 5'-ACG TCG CCG CAG GTC AGC AGG CTG CCT CTG CCC TCG CCG CTG CCG ATG GTG TCC TGG TCC TGC GC-3') and mAG-hGem (1/110) (5'-CAG CCT GCT GAC CTG CGG CGA CGT GGA GAA CCC CGG CCC CGT GAG CGT GAT CAA GCC CGA G-3' and 5'-ACG TCT CCA CAT GTC AGG CTT CCT CTT CCT TCT CCG CTT CCC AGC GCC TTT CTC CGT TTT TCT G-3'), and Pac (5'AAG CCT GAC ATG TGG AGA CGT GGA AGA AAA CCC TGG GCC CGC CAC CGA GTA CAA GCC CAC G-3' and 5'-TAA TCC AGA GGT TGA TTG GCT AGC TCA GGC ACC GGG CTT GCG GGT C-3'), from the FUCCI plasmid templates [13] and pGIPZ, respectively. Gibson assembly was used to create pLV-FUCCl, which encodes a T2A peptide linking mKO2-hCdt1 (30/120) with mAG-hGem (1/110), and a P2A peptide linking mAG-hGem (1/110) with Pac. To overcome difficulties caused by high GC-content in overlapping regions, the three inserts were joined using splicing by overlap extension (2) before addition to the assembly reaction. Supernatants containing lentiviral particles were generated in HEK293T cells using a $3^{\text {rd }}$ generation packaging system obtained from Addgene. Endothelial cells were incubated with lentivirus carrying the $\mathrm{FUCCI}$ reporter and a puromycin marker and cultured for up to 3-4 weeks in ECGM containing puromycin $(3 \mu \mathrm{g} / \mathrm{ml})$.

Following transduction with high-titre viral solutions generated in HEK293T cells, endothelial cells were transfected with specific siRNA duplexes for $48 \mathrm{~h}$ prior to being starved overnight in MCDB131 $+0.2 \%(\mathrm{w} / \mathrm{v}) \mathrm{BSA}$ and 2 $\mathrm{mM}$ thymidine (G1/S cell cycle arrest). Cells were subsequently trypsinised and reseeded into 96-well, black-walled plates at $2.5 \times 10^{3}$ cells per well in ECGM + $25 \mu \mathrm{M}$ 2-deoxycytidine and imaged at $8 \mathrm{~h}$ and $30 \mathrm{~h}$ post release following 
169 addition of Hoechst 33342 to visualise nuclear DNA. Image acquisition was 170 carried out using either a BD Pathway 435 imager or Olympus X81 171 immunofluorescence microscope equipped with $405 \mathrm{~nm}, 488 \mathrm{~nm}$, and $543 \mathrm{~nm}$ 172 light-source lines. Image analysis was performed using ImageJ and

\subsection{Cell viability assays}

3000 HUVECs were seeded per well of a 96-well plate, cultured in $90 \mu \mathrm{l}$ ECGM for $16-20 \mathrm{~h}$, before adding $10 \mu$ of MTS reagent (CellTiter 96 AQueous Non-Radioactive Cell Proliferation Assay, Promega, Madison, USA). After further incubation for $4 \mathrm{~h}$, colour change caused by reduction of the yellow tetrazolium compound (MTS) by metabolically active cells to brown formazan was monitored at $490 \mathrm{~nm}$ using a Tecan Sunrise plate reader (Mannedorf, Switzerland).

\subsection{Annexin $V$ apoptosis assay}

20000 HUVECs were seeded into 24-well plates and left overnight for 16-20 h. Media was removed and cells were subjected to RNAi and protein knockdown as previously described. Cells were gently detached from the substratum using previously described protocol for processing for flow cytometry. Before this was carried out, cells were centrifuged at $1000 \mathrm{~g}$ for 5 mins and resuspended in $0.5 \mathrm{ml}$ of Annexin $\mathrm{V}$ binding buffer using a kit (SigmaAldrich, Poole, UK). Annexin V-FITC conjugate (to stain apoptotic cells) and propidium iodide (to stain DNA of dead or dying cells) was added as recommended by manufacturer. Samples were then examined using a Fortessa flow cytometer (Becton Dickinson, UK) and >10000 labelled cells 
were analysed per experiment. Early apoptotic cells show labelling with the Annexin V-FITC conjugate alone. Live cells show no labelling with either the propidium iodide or Annexin V-FITC. Necrotic cells are labelled by both propidium iodide and Annexin V-FITC.

\subsection{Cell proliferation assay}

2000 HUVECs were seeded per well of a 96-well plate and left overnight for 16-20 h. Media was removed and replaced with serum-free medium for $3 \mathrm{~h}$, then stimulated with $0.25 \mathrm{nM}$ VEGF-A in $100 \mu \mathrm{l}$ for 24 h. $10 \mu \mathrm{M}$ BrdU was added per well at this point. Cell proliferation ELISA was used according to manufacturer's protocol (Roche Diagnostics, Mannheim, Germany). Colour change was developed using 3,3'5,5'-tetramethylbenzidine solution and the reaction quenched with $1 \mathrm{M} \mathrm{H}_{2} \mathrm{SO}_{4}$. Absorbance was measured at $450 \mathrm{~nm}$ using a variable wavelength Tecan Sunrise plate reader (Tecan, Mannedorf, Switzerland).

\subsection{Tubulogenesis assay}

Primary human foreskin fibroblasts (Promocell) were cultured in 48-well plates until confluent, before seeding 7500 endothelial cells per well onto the fibroblast monolayer and left overnight for 20-24 $\mathrm{h}$ essentially as previously described [9]. Briefly, media was aspirated and replaced with fresh media supplemented with VEGF-A (0.25 nM) every 2-3 days for 7 days. Co-cultures were fixed in $200 \mu \mathrm{l} 10 \%$ (v/v) formalin for $20 \mathrm{~min}$ at room temperature, quenched and labelled with mouse anti-human PECAM-1 (CD31) and donkey anti-mouse Alexa Fluor 594 conjugate as previously described [9]. Processed samples containing stained endothelial tubules were visualized using an EVOS-fl inverted digital microscope (ThermoFisher). 3 random fields were imaged per well. Total tubule length was then quantified from each 
224 photographic field using the open source software AngioQuant 225 (www.cs.tut.fi/sgn/csb/angioquant) and values averaged. For a more detailed 226 methods see elsewhere [9].

229 We used one-way analysis of variance (ANOVA) followed by Tukey's 230 post-hoc test or two-way ANOVA followed by Bonferroni multiple comparison 231 test using GraphPad Prism software (La Jolla, USA). Significant differences 232 between control and test groups were evaluated with $p$ values less than 0.05 $\left.\left.233\left(^{*}\right), 0.01^{(* *}\right), 0.001^{(* *}\right)$ and $\left.0.0001^{(* * *}\right)$ indicated on the graphs or 234 histograms. Error bars denote mean \pm SEM. 


\section{Results}

\subsection{ATF-2 modulates p21, p53 and Cyclin D1 levels}

In primary endothelial cells VEGF-A regulates signal transduction and cell proliferation [14] partially through recruitment of nuclear transcription factors, including c-fos and other AP-1 components [15]. We have previously identified a signalling nexus between VEGFR2, the MAP3K family member Tpl2, and a transcription factor, ATF-2. In previous studies on VEGF-Astimulated and ATF-2-regulated endothelial gene expression on VCAM-1 [15] and Tpl2 [16], we find that maximal VEGF-A 165 -stimulated, ATF-2-regulated VCAM-1 synthesis occurs $8 \mathrm{~h}$ after VEGF-A addition. Under such conditions, there is complexity in decreased VEGFR2 levels caused by increased ubiquitination, endocytosis and degradation [15]. However, there is also a rise in new VEGFR2 synthesis [15], which can also substantially add to VEGFR2 activation in the presence of excess exogenous VEGF-A. However, the influence of this pathway on endothelial cell cycle progression and survival was unknown. To ascertain whether different VEGF-A isoforms regulate cytosolic and nuclear signalling events which impact on the endothelial cell cycle, we probed the biochemical state of key regulatory proteins associated with such events (Fig. 1). As previously reported [17], two different VEGF-A isoforms (VEGF-A 165 and VEGF-A 121 ) show differential ability to activate VEGFR2, revealed by varied phospho-VEGFR2 (Y1175) levels (Fig. 1A). Such signalling further impacts on gene expression, as shown by increased levels of VCAM-1 in response to VEGF-A ${ }_{165}$ stimulation for $8 \mathrm{~h}$ (Fig. 1A). As ATF-2 is implicated in the VEGF-A-stimulated (after $8 \mathrm{~h}$ ) VCAM-1 increase, concomitant with a decrease in VEGFR2 levels [17], we depleted ATF-2 levels using RNA interference (RNAi) (Fig. 1A, 1B). Knockdown of ATF-2 levels resulted in $\sim 50 \%$ decrease in this essential nuclear regulator (Fig. 1B). However, ATF-2 knockdown did not affect levels of either Cyclin A2 or Cyclin B, critical drivers of cell proliferation (Fig. 1A). Unexpectedly, depletion of ATF-2 caused 
264 elevated levels of two other cell cycle regulators, Cyclin D1 and the cyclindependent kinase inhibitor, p21 (Fig. 1A). The latter is a major transcriptional target of the tumour suppressor p53, suggesting p53 involvement in the process.

There is link between VEGF-A-stimulated ATF-2 phosphorylation and ATF-2 levels $[15,16]$. Activation of the p53 tumour suppressor is known to increase levels of p21, a negative cell cycle regulator, thus potentially impacting additional cell cycle modifiers including Cyclin D1 [18-20]. We explored further links between ATF-2 and p53 by knockdown of either protein alone or together (Fig. 1C). As expected, ATF-2 knockdown abrogated the VEGF-A-stimulated increase in VCAM-1 expression (Fig. 1C, 1D). ATF-2 knockdown elevated p21 levels substantially. Importantly, p53 levels were also elevated under such conditions (Fig. 1C, 1E). The $>2$-fold increase in p53 levels caused by ATF-2 knockdown were reversed by p53 or combined ATF2/p53 knockdown (Fig. 1E). Under these conditions, ATF-2 knockdown caused 3.5-fold rise in Cyclin D1 levels (Fig. 1F). Furthermore, the increased p21 and cyclin D1 expression evident upon ATF-2 depletion were dependent on the presence of p53, as co-depletion of ATF-2 and p53 abolished the increases (Fig. 1C-F). However, VCAM1 levels were not rescued by depletion of both ATF-2 and p53 (Fig. 1D).

\subsection{Tp/2 dependence on ATF-2 and impact on p53 and Cyclin D1}

The MAP3K family member and oncoprotein, Tpl2, which is implicated in lung carcinogenesis [21] regulates VEGF-A-stimulated angiogenesis [22] and transduces signals from the cytosol to the nucleus in endothelial cells [16]. To assess whether Tpl2 is functionally linked to levels of ATF-2 and cell cycle regulators such as p53, we asked whether RNAi altered protein expression (Fig. 2A). Knockdown of Tpl2 caused $\sim 60 \%$ reduction in protein levels (Fig. 
2B). Tpl2 depletion also supressed ATF-2 expression to levels similar to those observed after direct ATF-2 knockdown (Fig. 2A). Surprisingly, although ATF2 knockdown caused $>2$-fold increase in p53, and Tpl2 depletion also reduced ATF-2 expression, Tpl2 RNAi had no substantial effect on p53, p21, or Cyclin D1 protein levels (Fig. 2A, 2D, 2E). However, combined depletion of both ATF2 and Tpl2 caused p53 and cyclin D1 protein levels, to return to baseline (Fig. $2 \mathrm{~A}, 2 \mathrm{D}, 2 \mathrm{E})$. Depletion of $\mathrm{Tpl} 2$ caused $>60 \%$ reduction in steady-state $\mathrm{Tpl} 2$ levels (Fig. 2B).

ATF-2 depletion elevates Tpl2 protein expression (Fig. 2A), indicative of a functional link between the two proteins. To explore this further we carried out qRT-PCR to analyse the link between ATF-2 and Tp/2 expression (Fig. 2C). In a comparison between control and VEGF-A-stimulated conditions, we found 15-fold increase in Tp/2 mRNA levels (Fig. 2C). Depletion of ATF-2 levels caused reduction in Tp/2 mRNA to background levels (Fig. 2C). ATF-2 knockdown elevates cell cycle regulator levels (cyclin D1, p53, p21) but Tpl2 depletion reverses such effects (Fig. 2D, 2E), suggesting Tpl2 expression is required for mediating the p53 increase evident upon ATF-2 knockdown. The presence of ATF-2 might act as a mitotic accelerator or enabler by dampening the expression of p53 and its downstream cell cycle inhibitors, including p21, via a mechanism dependent on Tpl2 activity.

The eukaryote cell cycle is regulated by a combination of protein kinases, cyclins and transcription factors [20, 23, 24]. The previous data in this study suggested that ATF-2 levels influences cell cycle proteins. To assess whether the endothelial cell cycle if affected by ATF-2, we used the fluorescent ubiquitinated cell cycle indicator (FUCCI) [13] which is a dual reporter system used to monitor progression through the cell cycle in living cells, tissues and animals [25]. A lentiviral $\mathrm{FUCCl}$ construct was used to transduce primary endothelial cells and cell synchronisation (see Materials and Methods) before monitoring of fluorescent reporter proteins, mKO2-hCdt1 (red) for non-cycling 
321 G1 stage cells, and mAG-hGem (green) for proliferating G2/M stage cells 322 (green) (Fig. 3A). Under control conditions, stimulation with VEGF-A caused 323 transient increase in the $\mathrm{G} 1: \mathrm{G} 2 / \mathrm{M}$ ratio after $8 \mathrm{~h}$ which is more than 2-fold 324 higher than that observed after $30 \mathrm{~h}$ (Fig. 3B), indicating a rise in the number of cells in G2/M phase within soon after VEGF-A stimulation. Here, depletion of either ATF-2 or p53 had no effect on the G1:G2/M ratio compared to controls (Fig 3B). However, combined ATF-2/p53 caused a significant >2fold increase in the proportion of cells in G2/M after $30 \mathrm{~h}$ (Fig 3B). Furthermore, knockdown of Tpl2 caused a dramatic rise in proportion of cells in the G2/M phase both at the $8 \mathrm{~h}$ and $30 \mathrm{~h}$ time points (Fig. 3B). However, the relative difference between the $8 \mathrm{~h}$ and $30 \mathrm{~h}$ time points was a 2-3-fold change in Tpl2depleted cells, similar to controls (Fig. 3B). Interestingly, combined ATF-2/Tpl2 knockdown showed little change between the $8 \mathrm{~h}$ and $30 \mathrm{~h}$ time points (Fig. $3 \mathrm{~B})$, suggesting substantial effects on the endothelial cell cycle.

Cells that are senescent or have exited the cell cycle are in G0, and p53 is a key regulator of cellular senescence [19]. One possibility is that depletion of cell cycle regulatory factors results in increased endothelial cell senescence or cell cycle exit. We evaluated the proportion (\%) of the endothelial cell population lacking staining for both $\mathrm{mAG}$ and $\mathrm{mKO}$ indicative of $\mathrm{G0}$ (Fig. 3C). This was substantially higher in the cells depleted of ATF-2 (Fig. 3C). However, this effect was rescued upon combined knockdown of either ATF-2/p53 or ATF2/Tpl2 (Fig. 3C). Furthermore, we found that in addition to cell cycle arrest, ATF-2 knockdown also resulted in $\sim 40 \%$ decrease in endothelial cell viability (Fig. 3D).

\subsection{ATF-2, Tp/2 and p53 modulation of apoptosis}

One question arising from these data is how endothelial cells integrate complex signal transduction pathways with nuclear gene expression to 
349 influence programmed (i.e. apoptosis) and general (i.e. necrosis) cell death. To address this, we used flow cytometry (see Materials and Methods) to identify, necrotic, early and late apoptotic endothelial cell populations (Fig. S1). We used controls (Fig. S1) to evaluate early and late apoptotic cells compared to necrotic cells under conditions of specific protein depletion (Fig. S1B). Quantification of the AnxV-positive population revealed $\sim 4$-fold rise in such endothelial cells upon ATF-2 depletion (Fig. 4A). Tpl2 depletion also caused $>2$-fold rise in AnxV-labelled cell population compared to control (Fig. 4A). A similar profile was observed when the relative cell population was analysed with early apoptotic cell population marked increased $>2$-fold upon either ATF2 or Tpl2 depletion (Fig. 4B). In the analysis of late apoptotic cells, ATF-2 depletion caused a>4-fold rise in apoptotic cells, and only a $\sim 2$-fold rise in Tpl2depleted cells (Fig. 4C). Considering the total apoptotic cell population, the ATF-2 or Tpl2-depleted cells all show significant 2-3-fold rise in apoptosis (Fig. 4D). In these flow cytometry experiments, simultaneous depletion of ATF2/Tpl2 or ATF-2/p53 causes a reversal in the effects observed with ATF-2 depletion alone (Fig. 4A-4D).

To explore the molecular basis for increased endothelial apoptosis caused by ATF-2 depletion, we assessed the biochemical status of key apoptotic regulators (Fig. 4E). Immunoblotting of control (scrambled) and ATF2-depleted endothelial cells revealed an increase in cleaved pro-apoptotic Caspase 3 (Fig. 4E). There were also increased levels of p53 and pro-apoptotic Bax proteins in ATF-2-depleted cells (Fig. 4E). Quantification of these data showed $>2$-fold rise in cleaved Caspase 3 upon ATF-2 depletion (Fig. 4F).

3.4. ATF-2, Tp/2 and p53 involvement in VEGF-A-regulated endothelial cell responses

VEGF-A promotes multiple endothelial responses including cell viability, cell proliferation and tubule formation, key features of angiogenesis [4, 5]. We compared endothelial cell viability upon knockdown of specific cytosolic and 
379 nuclear factors: ATF-2 knockdown caused $~ 50 \%$ decrease in VEGF-A380 stimulated cell viability (Fig. $5 \mathrm{~A}$ ). Tpl2 knockdown also caused $\sim 30 \%$ decrease in VEGF-A-stimulated cell viability (Fig. 5A). However, simultaneous combined knockdown of either ATF-2/p53, or ATF-2/Tpl2 caused cell viability to return to baseline levels (Fig. 5A). Depletion of p53 alone had no effect on VEGF-Astimulated endothelial cell viability (Fig. 5A).

As VEGF-A is well-known to stimulate cell proliferation, we asked 386 whether this response was affected by knockdown of components of signal transduction pathways involving ATF-2 and Tpl2 (Fig. 5B). ATF-2 knockdown caused $\sim 30 \%$ decrease in endothelial cell proliferation; however, knockdown of p53 or Tpl2 had no effect (Fig. 5B). However, simultaneous knockdown of ATF-2/p53 or ATF-2/Tpl2 returned cell proliferation to control baseline levels (Fig. 5B).

One unique feature of VEGF-A is the capacity to stimulate endothelial cells to proliferate, migrate and form biological tubes [26]. We used the in vitro endothelial-fibroblast co-culture assay to evaluate VEGF-A-stimulated tubulogenesis (Fig. 5C). VEGF-A stimulation causes $\sim 6$-fold increase in average endothelial tubule length under control conditions (Fig. 5D). In contrast, ATF-2 knockdown caused $\sim 50 \%$ decrease in endothelial tubule length, (Fig. 5D). Although Tpl2 knockdown caused $\sim 4$-fold increase in VEGFA-stimulated tubule length, there was $\sim 35 \%$ reduction in tubulogenesis compared to control (Fig. 5D). Again however, combined knockdown of either ATF-2/p53 or ATF-2/Tpl2 caused return to baseline levels of VEGF-Astimulated endothelial tubulogenesis (Fig. 5D). Lack of ATF-2 hampers endothelial tubule formation through upregulation of p53 expression and 404 induction of cell cycle arrest, all dependent on the presence of Tpl2. 


\section{Discussion}

One important aspect feature of primary cells and tissues is the balance between cell survival, proliferation and different types of cell death. Complex regulatory mechanisms exist to ensure correct timing of cell proliferation in healthy and diseased states. In this study, we investigated how endothelial cells balance cytosolic and nuclear signalling which impacts on cell cycle progression and cell death. Our study suggests a model where Tpl2 receives signals and modulates the activity of downstream factors which regulate gene expression and cell cycle progression (Fig. 6). A balance between Tpl2 signalling and ATF-2 nuclear activity is required for normal endothelial responses (Fig. 6A). Reduction in ATF-2 activity impacts on the endothelial commitment to cell cycle progression and apoptosis (Fig. 6B). This function appears dependent on the presence of Tpl2.

The evidence for this model is based on 4 lines of evidence. Firstly, ATF2 depletion promotes a rise in p53, p21 and Cyclin D1 levels, but other cyclins are not affected. This suggests that under such conditions, these endothelial cells have entered a pro-apoptotic phase coincident with cell cycle arrest. Secondly, reduction in ATF-2 levels also causes a rise in the proportion of cell population in senescence (G0), and this coincides with decreased endothelial cell viability. Thirdly, a reduction in Tpl2 levels cause a corresponding decrease in ATF-2 levels, although this was not accompanied by elevated p53, p21, or Cyclin D1 expression, suggesting a functional link between these two proteins, where Tpl2 may be viewed as a master regulator. Importantly, ATF-2 depletion blocks the VEGF-A-stimulated rise in Tpl2 levels, suggesting ATF-2 regulates gene transcription of the Tp/2 locus. Moreover, loss of ATF-2 is reversed by simultaneous depletion of either Tpl2 or p53, suggesting a regulatory pathway linking all three proteins (Fig. 6). Finally, such regulatory effects are manifested in VEGF-A-stimulated endothelial tubulogenesis, which requires coordination of cell proliferation and migration for biological tube formation. Reduction in 
ATF-2 levels also reduces the efficiency of endothelial tubulogenesis; however, such effects are reversed by simultaneous depletion of either Tpl2 or p53. This regulatory pathway (Fig. 6) thus impacts on the VEGF-A-stimulated formation of biological tubes.

The tumour progression locus 2 (Tpl2/Cot/MAP3K8) gene product was originally identified as a serine/threonine protein kinase in T-cells which regulated signal transduction and cellular responses [27]. Tpl2 is also a protooncoprotein, conferring resistance to Raf kinase inhibition [28], promoting breast cancer [29], keratocanthoma and squamous cell carcinoma [30]. However, its role in the vascular system is less well-studied, but reports suggest that it can regulate angiogenesis [22] and diabetic retinopathy [31]. Our studies now suggest that cytosolic Tpl2 and the nuclear transcription factor ATF-2, are part of a pathway that controls cell cycle progression and apoptosis. The communication between Tpl2 and ATF-2 may occur directly: hyperphosphorylation of ATF-2 is implicated with increased signalling through the MAPK pathway [15]. Recent studies suggest that pharmacological inhibition of p38 MAPK, JNK and AKT signal transduction pathways had little or no effect on ATF-2 phosphorylation in endothelial cells [15]. One possibility is that signalling through the canonical MAPK pathway leads to Tpl2 phosphorylation, activation and translocation into the nucleus in a manner analogous to ERK1/2. It has been reported that Tpl2 activity is required for phosphorylation of nuclear factors including ATF-2 [16, 32], implying a functional role in nuclear gene expression. Importantly, a direct nuclear role of Tpl2 has also been reported [30]. This raises the possibility of Tpl2 itself responding to VEGFR2 activation, phosphorylation via canonical (MAPK) or non-canonical pathways which enables nuclear translocation, transcription $p$ factor phosphorylation and modulation of nuclear gene transcription. In endothelial cells, VEGF-A-stimulated signal transduction through a noncanonical signal transduction pathway involving the MEK5-ERK5 axis impacts 
on a range of vascular responses [33], which could have relevance to Tpl2 regulation in this context. In tumour cells, there is evidence that Tpl2 activity is linked to ERK5 status [34].

There is a notable relationship between Tpl2 and ATF-2 levels. Decreased Tpl2 levels also cause a substantive decrease in ATF-2 levels; combined ATF-2/Tpl2 knockdown reverses effects caused by ATF-2 depletion alone. However, decreased ATF-2 levels alone, increase Tpl2, p53, cyclin D1 and p21 levels; this is not evident when Tpl2 is depleted in isolation, despite ATF-2 levels also falling. Tpl2 expression or activity, appears necessary to allow ATF-2 depletion to stabilise or activate p53, and promote cell cycle arrest. One explanation is that decreased ATF-2 phosphorylation, due to loss of upstream Tpl2, increases post-translational modifications on ATF-2 leading to increased proteolysis and clearance. The loss of ATF-2 leading to increased Tpl2 (Fig. 6B) could be explained by a possible role for ATF-2 in repressing TPL2 nuclear gene expression. Alternatively, ATF-2 could activate transcription of genes encoding ubiquitin ligases; such enzymes could target components of the Tpl2-regulated pathway. Protein phosphorylation and ubiquitination are strongly linked in many signal transduction pathways to control signalling and protein levels. As p53 undergoes complex posttranslational modifications including phosphorylation and ubiquitination [35], one explanation is that decreased ubiquitination due to reduced ATF-2 activity could drive increased p53 levels. Indeed, Tpl2 has been shown to regulate the activity of the main p53 E3 ubiquitin ligase, HDM2 [30]. ATF-2 loss may activate Tpl2 to reduce HDM2 activation or expression, allowing p53 to escape proteasomal degradation and undergo nuclear accumulation. Furthermore, both p21 and Cyclin D1 are also regulated by ubiquitination and proteolysis, suggesting that ATF-2-regulated gene expression could have impact in this context. 
In conclusion, our study shows that in primary endothelial cells, basal and

493

494

495

496

497

498

499

500

501

502

503

504

505

506

507

508

509

510

511

512

513

514

515

516

517

ligand-activated signalling pathways are tightly regulated to ensure that signals from the cytosol impact on nuclear gene expression and nuclear protein function. A major finding is that a signalling axis involving Tpl2 serine/threonine protein kinase and ATF-2 transcription factor with a wider impact on key cell cycle regulators such as p53, p21 and Cyclin D1. This work also raises new questions on the mechanisms of gene expression and the nature of posttranslational modifications that govern the levels of key cell cycle regulators.

\section{Conflict of interest}

The authors have no conflict of interest.

\section{Contributors}

G. W. Fearnley designed research, designed and performed experiments, interpreted results, wrote and revised the manuscript. A. M. Latham performed experiments and provided data. A. F. Odell designed research, designed and performed experiments, interpreted results and revised the manuscript. M. Hollstein helped to design experiments and carry out the work. S. Ponnambalam designed research, interpreted results, wrote and revised the manuscript.

\section{Acknowledgments}

We thank Annette Weninger for help with the qRT-PCR studies. We thank the members of the Endothelial Cell Biology Unit for advice and support. This work was supported by a grant from Yorkshire Cancer Research (AFO) and Heart Research UK (TRP11/11). 


\section{References}

519 [1] Proud CG, Cold Spring Harbor Persp Biol. 2019; 11:a033050.

520 [2] Lemmon MA, Schlessinger J, Cell. 2010;141:1117-1134.

521 [3] Lemmon MA, Freed DM, Schlessinger J, Kiyatkin A, Cell. 2016;164:1172-1184.

522 [4] Bates DO, Beazley-Long N, Benest AV, Ye X, Ved N, Hulse RP, Barratt S, Machado MJ,

Donaldson LF, Harper SJ, Peiris-Pages M, Tortonese DJ, Oltean S, Foster RR, Comp Physiol. 2018;8:955-979.

[5] Apte RS, Chen DS, Ferrara N, Cell. 2019;176:1248-1264.

[6] Simons M, Gordon E, Claesson-Welsh L, Nat Rev Mol Cell Biol. 2016;17:611-625.

[7] Smith GA, Fearnley GW, Harrison MA, Tomlinson DC, Wheatcroft SB, Ponnambalam S, J Inherit Metab Dis. 2015;38:753-763.

[8] Smith GA, Fearnley GW, Tomlinson DC, Harrison MA, Ponnambalam S, Biosci Rep. 2015;35:e00253.

[9] Fearnley GW, Smith GA, Odell AF, Latham AM, Wheatcroft SB, Harrison MA, Tomlinson DC, Ponnambalam S, Meth Enzymol. 2014;535:265-292.

[10] Fearnley GW, Wheatcroft SB, Ponnambalam S, Meth Mol Biol. 2015;1332:49-65.

[11] Uhrig $M$, Ittrich $C$, Wiedmann V, Knyazev $Y$, Weninger $A$, Riemenschneider $M$, Hartmann T, PLoS One. 2009;4:e6779.

[12] Ernst T, Hergenhahn M, Kenzelmann M, Cohen CD, Bonrouhi M, Weninger A, Klaren R, Grone EF, Wiesel M, Gudemann C, Kuster J, Schott W, Staehler G, Kretzler M, Hollstein M, Grone HJ, Am J Pathol. 2002;160:2169-2180.

[13] Sakaue-Sawano A, Kurokawa H, Morimura T, Hanyu A, Hama H, Osawa H, Kashiwagi S, Fukami K, Miyata T, Miyoshi H, Imamura T, Ogawa M, Masai H, Miyawaki A, Cell. 2008;132:487-498.

[14] Wu LW, Mayo LD, Dunbar JD, Kessler KM, Baerwald MR, Jaffe EA, Wang D, Warren RS, Donner DB, J Biol Chem. 2000;275:5096-5103.

[15] Fearnley GW, Odell AF, Latham AM, Mughal NA, Bruns AF, Burgoyne NJ, HomerVanniasinkam S, Zachary IC, Hollstein MC, Wheatcroft SB, Ponnambalam S, Mol Biol Cell. 2014;25:2509-2521.

[16] Fearnley GW, Abdul-Zani I, Latham AM, Hollstein MC, Ladbury JE, Wheatcroft SB, Odell AF, Ponnambalam S, Biol Open. 2019;8:bio034215.

[17] Fearnley GW, Bruns AF, Wheatcroft SB, Ponnambalam S, Biol Open. 2015;4:731-742.

[18] Klein EA, Assoian RK, J Cell Sci. 2008;121:3853-3857.

[19] Bieging KT, Mello SS, Attardi LD, Nat Rev Cancer. 2014;14:359-370.

[20] Engeland K, Cell Death Differ. 2018;25:114-132.

[21] Gkirtzimanaki K, Gkouskou KK, Oleksiewicz U, Nikolaidis G, Vyrla D, Liontos M, Pelekanou V, Kanellis DC, Evangelou K, Stathopoulos EN, Field JK, Tsichlis PN, Gorgoulis V, Liloglou T, Eliopoulos AG, Proc Natl Acad Sci USA. 2013;110:E1470-1479.

[22] Lee WJ, Lan KH, Chou CT, Yi YC, Chen WC, Pan HC, Peng YC, Wang KB, Chen YC, Chao TH, Tien HR, Sheu WH, Sheu ML, Neoplasia. 2013;15:1036-1048.

[23] Dominguez-Brauer C, Brauer PM, Chen YJ, Pimkina J, Raychaudhuri P, Cell Cycle. 2010;9:86-89. 
560 [24] Gordon EM, Ravicz JR, Liu S, Chawla SP, Hall FL, Mol Clin Oncol. 2018;9:115-134.

561 [25] Sakaue-Sawano A, Miyawaki A, Cold Spring Harbor Prot. 2014:pdb.prot080408.

562 [26] Chung AS, Ferrara N, Annu Rev Cell Dev Biol. 2011;27:563-584.

563 [27] Xu D, Matsumoto ML, McKenzie BS, Zarrin AA, Pharmacol Res. 2018;129:188-193.

564 [28] Johannessen CM, Boehm JS, Kim SY, Thomas SR, Wardwell L, Johnson LA, Emery 565 CM, Stransky N, Cogdill AP, Barretina J, Caponigro G, Hieronymus H, Murray RR, Salehi566 Ashtiani K, Hill DE, Vidal M, Zhao JJ, Yang X, Alkan O, Kim S, Harris JL, Wilson CJ, Myer 567 VE, Finan PM, Root DE, Roberts TM, Golub T, Flaherty KT, Dummer R, Weber BL, Sellers 568 WR, Schlegel R, Wargo JA, Hahn WC, Garraway LA, Nature. 2010;468:968-972.

569 [29] Kim G, Khanal P, Kim JY, Yun HJ, Lim SC, Shim JH, Choi HS, Mol Carcinogenesis. $570 \quad 2015 ; 54: 440-448$.

571 [30] Lee JH, Lee JH, Lee SH, Do SI, Cho SD, Forslund O, Inn KS, Lee JS, Deng FM, 572 Melamed J, Jung JU, Jeong JH, Cancer Res. 2016;76:6712-6722.

573 [31] Lai DW, Lin KH, Sheu WH, Lee MR, Chen CY, Lee WJ, Hung YW, Shen CC, Chung 574 TJ, Liu SH, Sheu ML, Circ Res. 2017;121:e37-e52.

575 [32] Kanellis DC, Bursac S, Tsichlis PN, Volarevic S, Eliopoulos AG, Oncogene. 576 2015;34:2516-2526.

577 [33] Roberts OL, Holmes K, Muller J, Cross DA, Cross MJ, J Cell Sci. 2010;123:3189-3200.

578 [34] Wang X, Gocek E, Novik V, Harrison JS, Danilenko M, Studzinski GP, Cell Cycle. 579 2010;9:4542-4551.

580 [35] Meek DW, Biochem J. 2015;469:325-346. 


\section{FIGURE LEGENDS}

Figure 1. VEGF-A-regulated gene expression exhibits dependence on ATF-2 and p53. (A) Endothelial cells subjected to treatment with siRNA duplexes (scrambled or ATF-2) were treated under serum-free (SF), normal growth media or VEGF-A $A_{165}$ or VEGF-A $A_{121}$ isoforms for $8 \mathrm{~h}$ followed by lysis and immunoblotting (see Materials and Methods). Blots were probed using antibodies specific for phospho-VEGFR2 (pY1175), VEGFR2, VCAM-1, ATF2, p21, actin, cyclins A2, B or D1. (B) Quantification of relative ATF-2 levels after treatment with control (scrambled siRNA) or ATF-2 siRNA duplexes. (C) Endothelial cells subjected to treatment with control untreated, scrambled, ATF-2 and ATF-2/p53 combined siRNA duplexes were non-stimulated (-) or treated with VEGF-A $A_{165}$ or VEGF-A ${ }_{121}$ isoforms $(+)$ followed by lysis, and immunoblotting with antibodies specific for phospho-VEGFR2, VEGFR2, VCAM-1, p53, p21, phospho-ATF-2, ATF-2, cyclin D1 or tubulin. (D) Quantification of relative levels of VCAM-1 levels in control, scrambled, ATF-2, p53 and combined ATF-2/53 siRNA treatments under normal starvation (control) or VEGF-A 165 isoform (165) stimulation. (E) Quantification of relative p53 levels in control, scrambled, ATF-2, p53 and combined ATF-2/53 siRNA treatments. (F) Quantification of relative levels of cyclin D1 levels after treatment with control, scrambled, ATF-2, p53 and combined ATF-2/53 siRNA duplexes. Error bars indicate \pm SEM $(n \geq 3)$; significance is indicated by the asterisks shown when $\left.\left.\left.p<0.05\left(^{*}\right), p<0.01{ }^{(* *}\right), p<0.001{ }^{* * *}\right), p<0.0001{ }^{(* * *}\right)$.

Figure 2. ATF-2 and Tpl2 regulate p53 and cyclin D1 levels in endothelial cells. (A) Endothelial cells subjected to treatment with control untreated, scrambled, ATF-2 or combined ATF-2/p53 siRNA duplexes were lysed and immunoblotted with antibodies specific for VEGFR2, p53, p21, Tpl2, phosphoATF-2, ATF-2, cyclin D1 and tubulin. (B, D, E) Quantification of relative protein levels of (B) Tpl2, (D) p53, and (E) cyclin D1 after treatment with different 
siRNA duplexes. (C) Quantification of relative Tp/2 RNA levels after treatment with control or ATF-2-specific siRNA duplexes. HUVECs treated with either control scrambled siRNA or ATF-2-specific siRNA duplexes, serum starved for $2 \mathrm{~h}$, stimulated with VEGF-A before lysis and qRT-PCR analysis (see Materials and Methods). Tp/2 RNA levels were normalised relative to control siRNA treatment. (B-E) Error bars indicate $\pm \operatorname{SEM}(n \geq 3)$; significance is indicated by the asterisks shown when $\left.\left.p<0.05\left(^{*}\right), p<0.01{ }^{* *}\right), p<0.001{ }^{(* * *}\right), p<0.0001$ $(* * * *)$.

Figure 3. The endothelial cell cycle shows regulation by ATF-2, Tp/2 and p53. (A) Endothelial cells stably expressing the FUCCI reporter (see Materials and Methods) were subjected to treatment with scrambled, ATF-2, p53 and Tpl2 siRNA duplexes followed by synchronization and stimulation with $0.25 \mathrm{nM}$ VEGF-A ${ }_{165}($ VEGF-A) for $8 \mathrm{~h}$ or $30 \mathrm{~h}$ before fixation and visualization using fluorescence microscopy. Quantification of endothelial cell populations after treatment with scrambled, ATF-2, p53 and Tpl2, ATF-2/p53, ATF-2/Tpl2 siRNA duplexes as shown in (B) G1/M, and (C) G0. (D) Quantification of endothelial viability in cells subjected to treatment with control, scrambled or ATF-2 siRNA duplexes. Error bars indicate $\pm \operatorname{SEM}(n \geq 3)$; significance is indicated by the asterisks shown when $p<0.05\left(^{*}\right), p<0.01\left(^{* *}\right), p<0.001\left(^{* * *}\right)$.

Figure 4. ATF-2 levels influence endothelial cell apoptosis. (A-D) Endothelial cells were subjected to untreated control, scrambled, ATF-2, p53, Tpl2, ATF-2/p53, ATF-2/Tpl2 siRNA duplexes before flow cytometry analysis using combined propidium iodide and Annexin V-FITC staining (see Materials and Methods). Quantification of (A) AnnexinV-labelled cell population, (B) early apoptotic cells, (C) late apoptotic cells, and (D) total apoptotic cells after treatment with different siRNA duplexes followed by flow cytometry. Error bars indicate \pm SEM $(n \geq 3$ ); significance is indicated by the asterisks shown when 
$\left.641 p<0.05^{(*)}, p<0.001{ }^{* * *}\right) .(E)$ Endothelial cells subjected to treatment with 642 scrambled or ATF-2-specific siRNA duplexes were lysed and immunoblotted 643 with antibodies specific for ATF-2, cleaved caspase 3, caspase 3, p53, Bax 644 and tubulin. (F) Quantification of relative levels of cleaved Caspase 3 in 645 646 647 648 649 650 651 652 653

Figure 5. ATF-2, Tpl2 and p53 levels modulate endothelial cell viability, proliferation and tubulogenesis. Quantification of endothelial cell (A) viability, (B) proliferation, and (C) tubulogenesis after treatment with different siRNA duplexes as indicated in each panel. In panel C, endothelial cells were treated with different siRNA duplexes before assaying for tubulogenesis (see Materials and Methods) by growth in normal medium (control) or VEGF-A $A_{165}$ stimulated (165) tubulogenesis. In panels A-C, error bars indicate $\pm \operatorname{SEM}(n \geq 3)$; significance is indicated by the asterisks shown when $p<0.05\left(^{*}\right), p<0.01\left(^{* *}\right)$, $\left.\left.p<0.001{ }^{(* *}\right), p<0.0001{ }^{* * * *}\right)$. (D) Endothelial cells were treated with different siRNA duplexes (scrambled, ATF-2, p53, Tpl2, ATF-2/p53, ATF-2/Tpl2) before assaying for tubulogenesis. PECAM-1 staining was used for detecting endothelial tubules using fluorescence microscopy (see Materials and Methods). Bar, $1000 \mu \mathrm{m}$.

Figure 6. Regulation of endothelial cell cycle progression and apoptosis by ATF-2, p53 and Tpl2. (A) Under normal or steady-state conditions, the Tpl2 protein kinase maintains ATF-2 phosphorylation (Step 1) which negatively regulates p53 levels, impacting on p21 and cyclin D1 expression (Step 2). ATF2 also negatively regulates $\mathrm{Tpl} 2$ levels. This translates into normal endothelial cell cycle progression and function (Step 3). (B) Under conditions of reduced ATF-2 activity or levels there is a rise in Tpl2 levels (Step 4) which positively 
670 regulates p53 levels, impacting on p21 and cyclin D1 expression (Step 5). This 671 translates into cell cycle arrest and apoptosis (Step 6). 
Figure 1

A

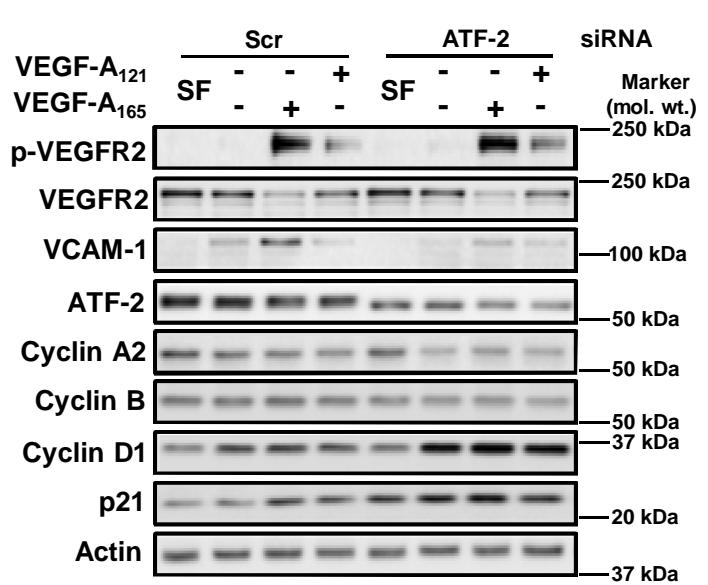

C VEGF-A $\frac{\text { Con }}{121} \frac{\text { Scr }}{-++} \frac{\text { ATF-2 }}{-++} \frac{\text { p53 }}{-++} \frac{\text { ATF-2/p53 }}{--+}$

VEGF-A $_{165}++-+-+-\cdot+-+\cdot$

p-VEGFR2-Y1175 - - $250 \mathrm{kDa}$ VEGFR2 $-250 \mathrm{kDa}$ VCAM-1 E-C-PE- $100 \mathrm{kDa}$ p53

p21

Cyclin D1

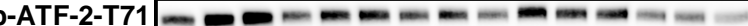
ATF-2

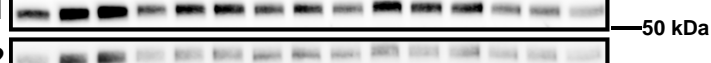

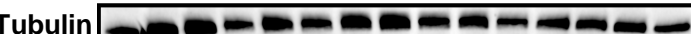
$50 \mathrm{kDa}$ $\mathbf{E}$

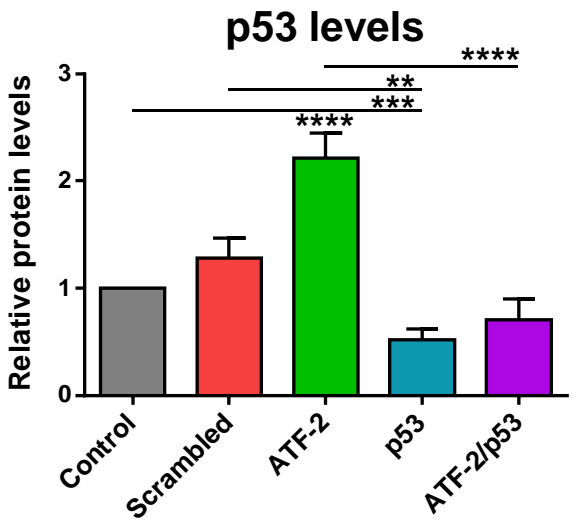

RNAi treatment
B

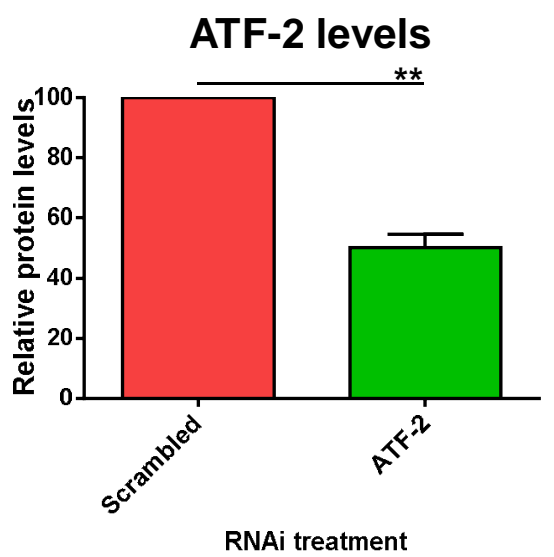

D

VCAM-1 levels

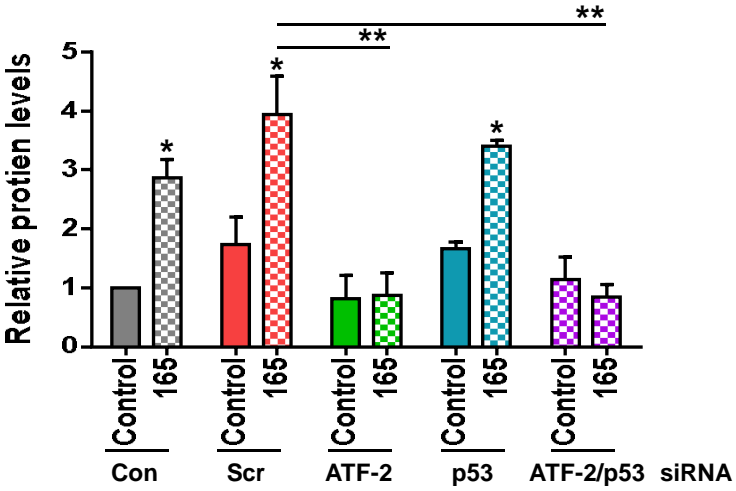

$\mathbf{F}$

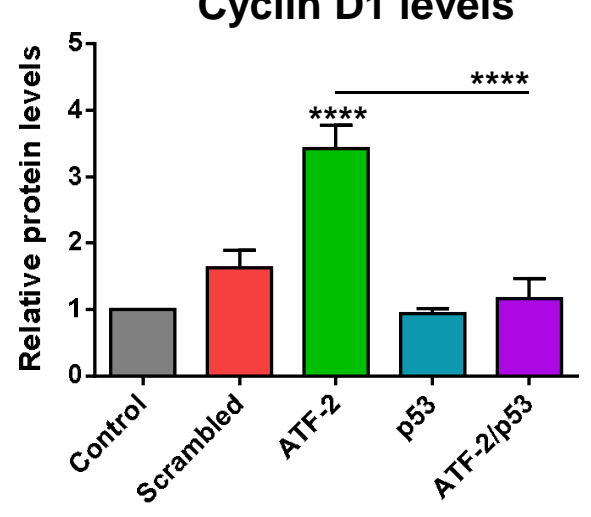

RNAi treatment 
Figure 2
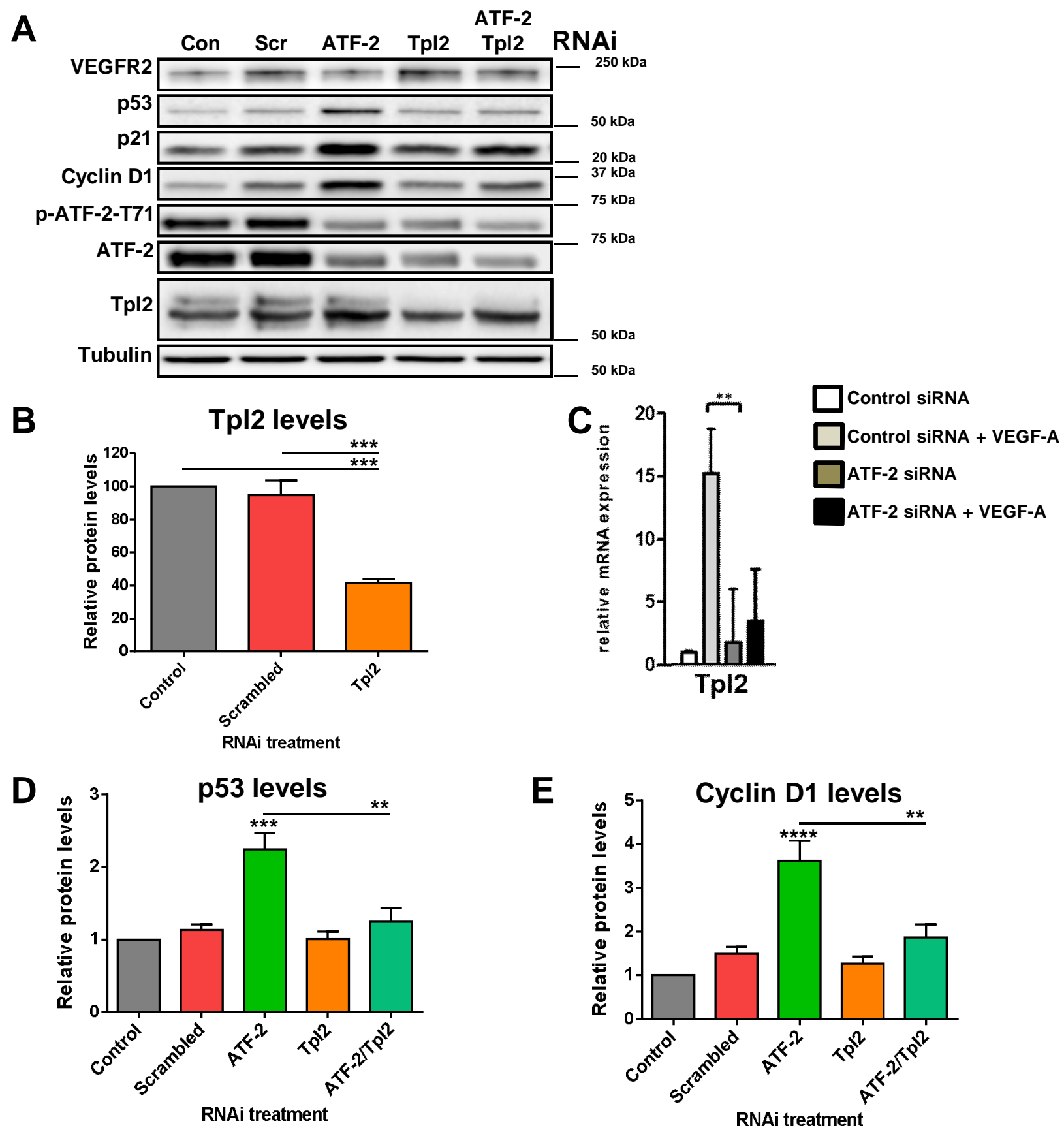
Figure 3

A Scrambled siRNA ATF-2 siRNA
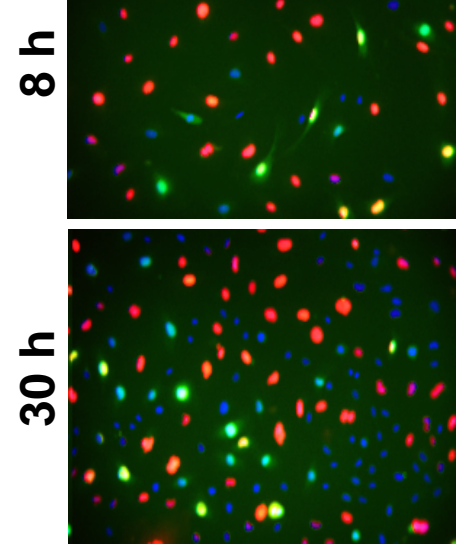

p53 siRNA
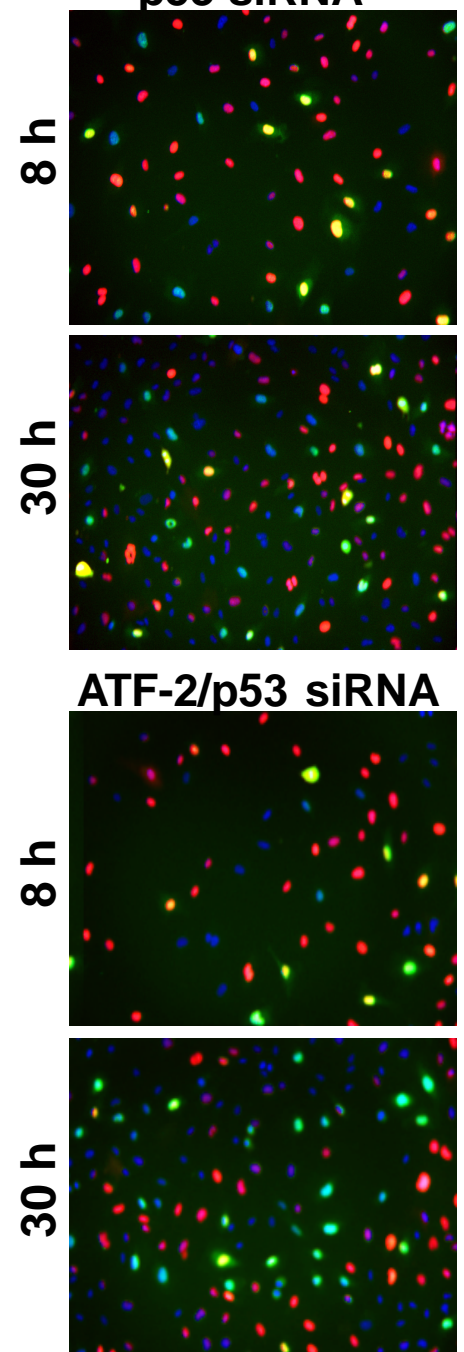

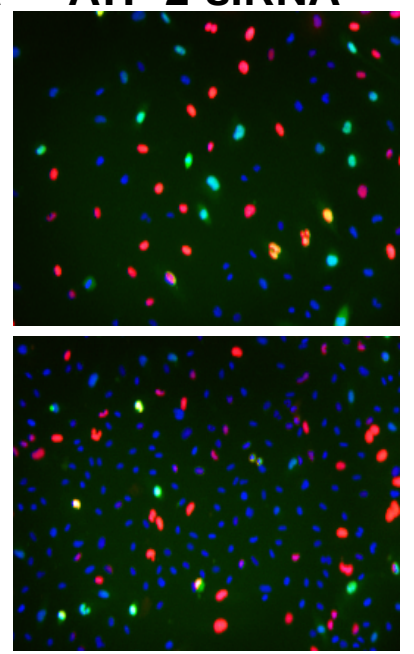

Tpl2 siRNA

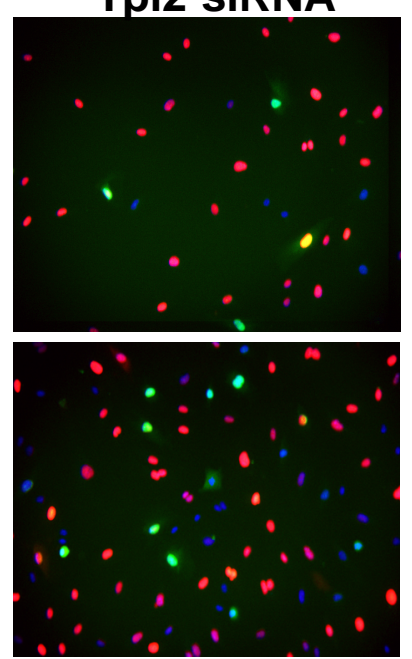

ATF-2/Tpl2 siRNA
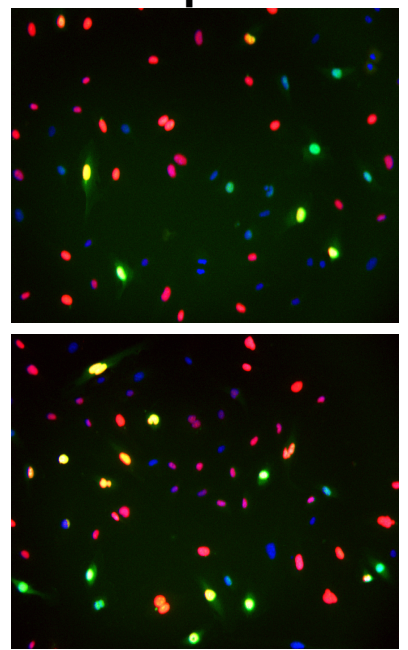

B

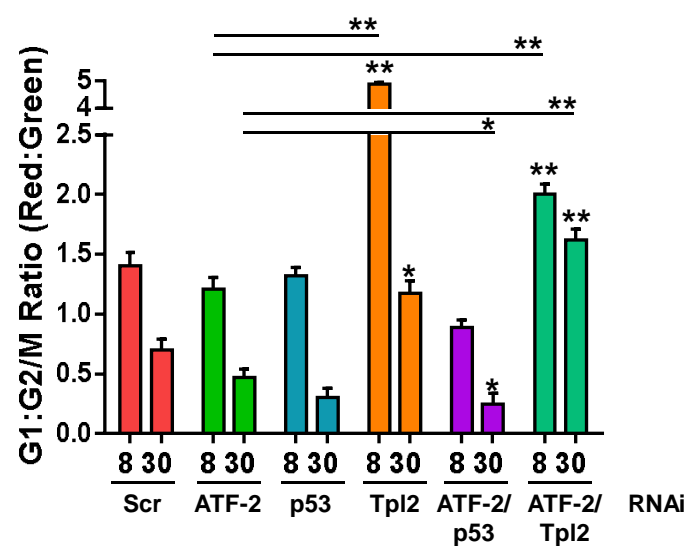

\section{C}

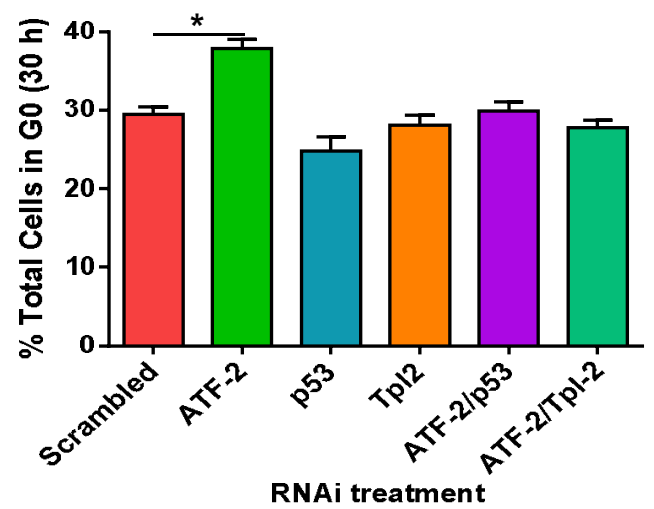

D

Cell viability

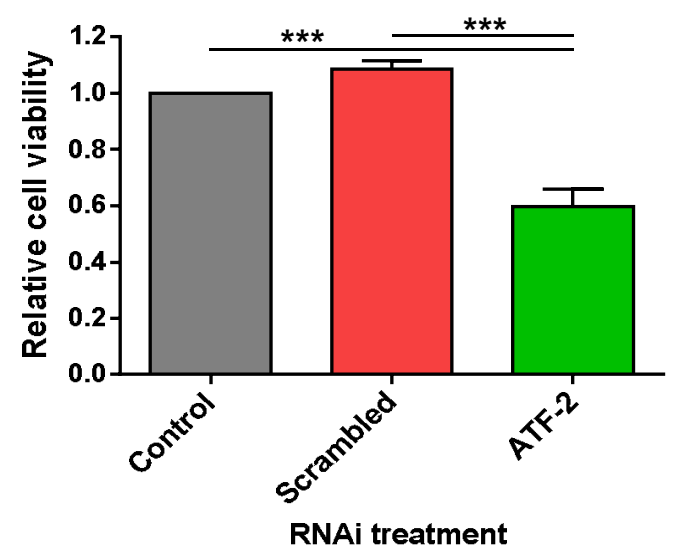


Figure 4
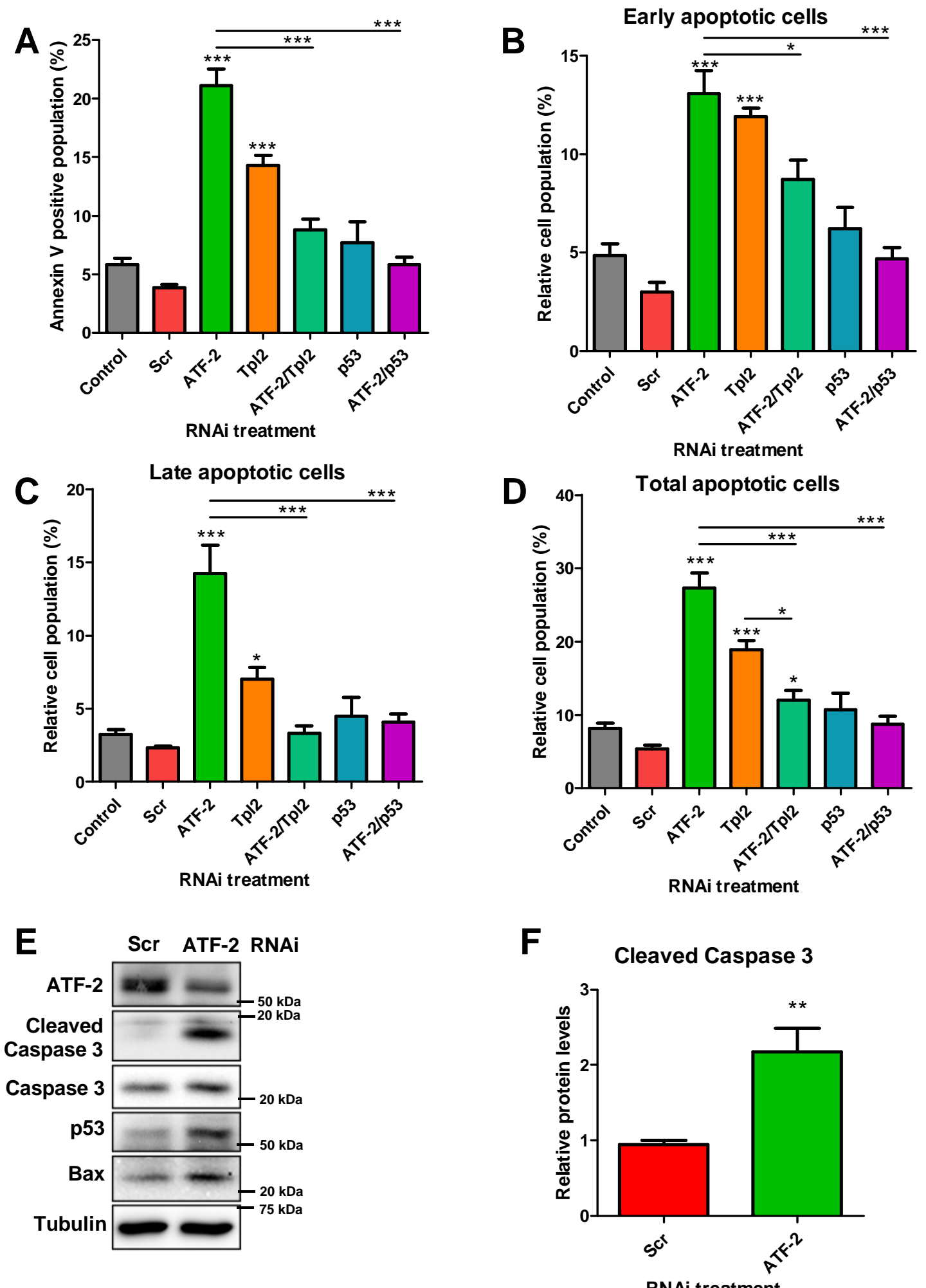

RNAi treatment 
Figure 5

A

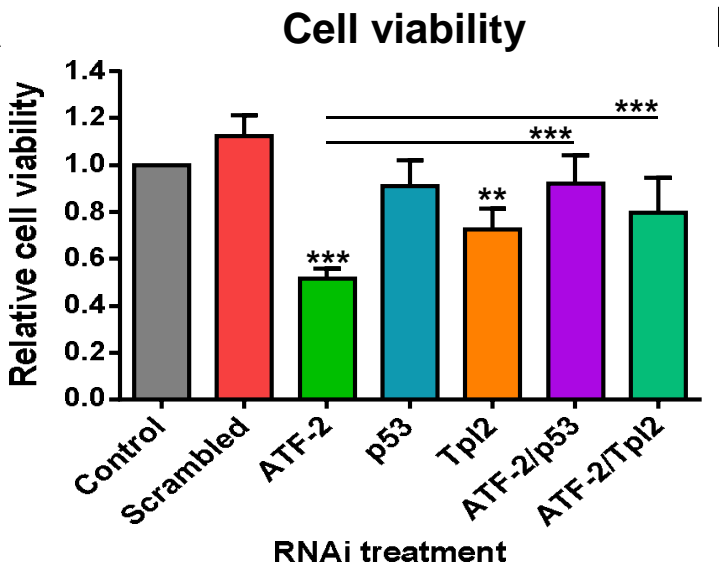

B

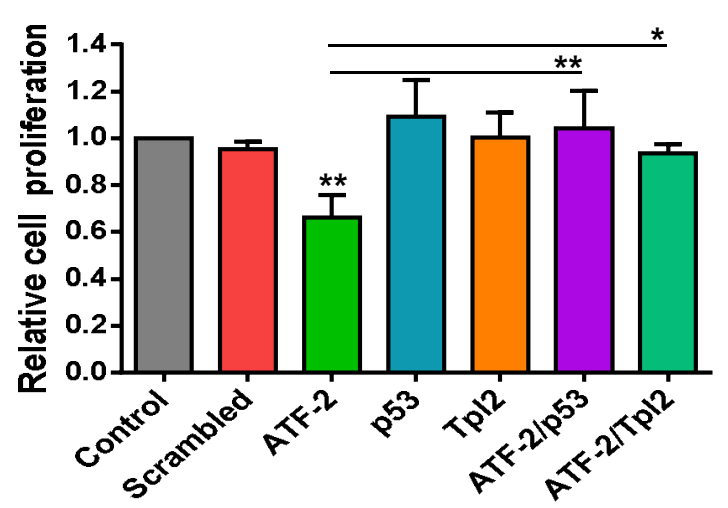

C

RNAi treatment

Tubulogenesis

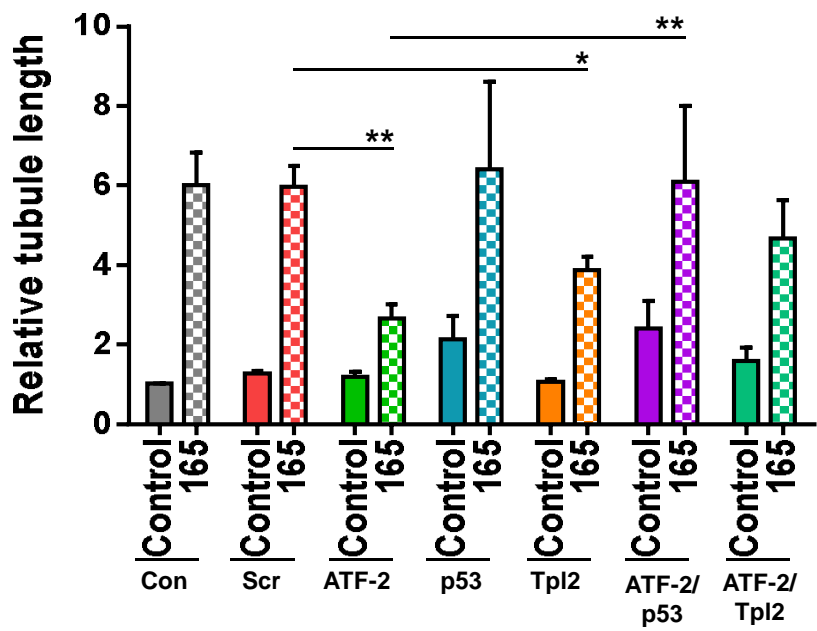

D

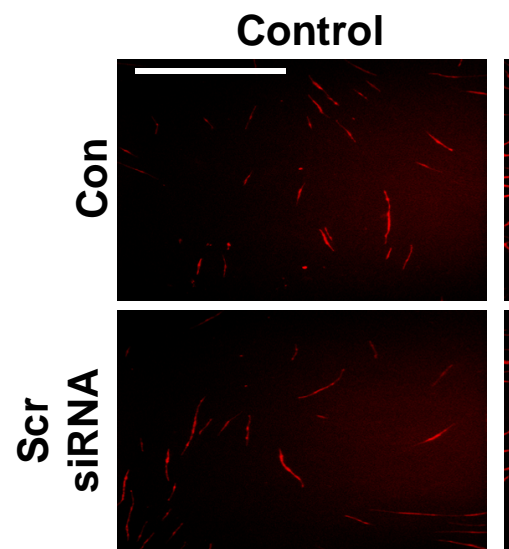

贞石品

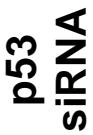

$\frac{N}{2} \frac{4}{n}$

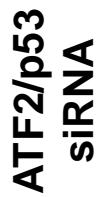

$\frac{N}{2} \frac{1}{\frac{N}{2}}$
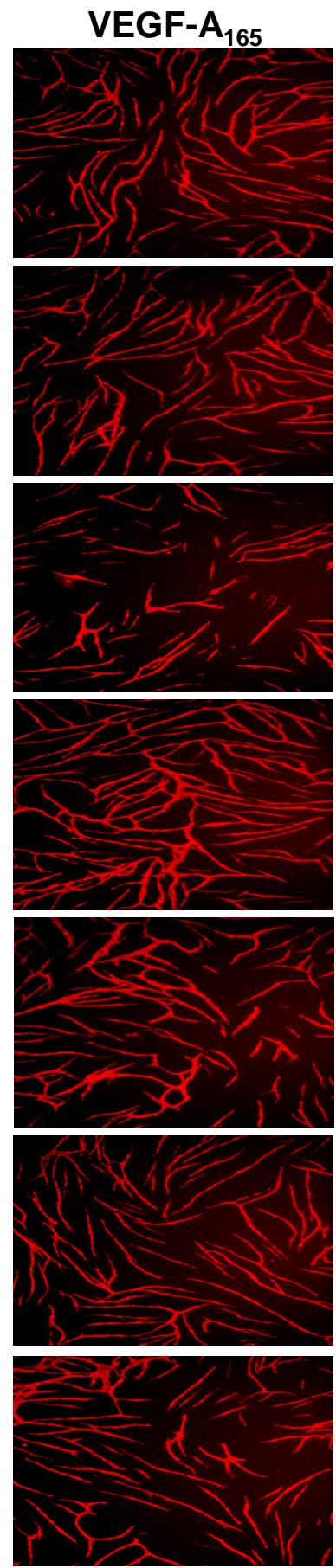

RNAi 
Figure 6

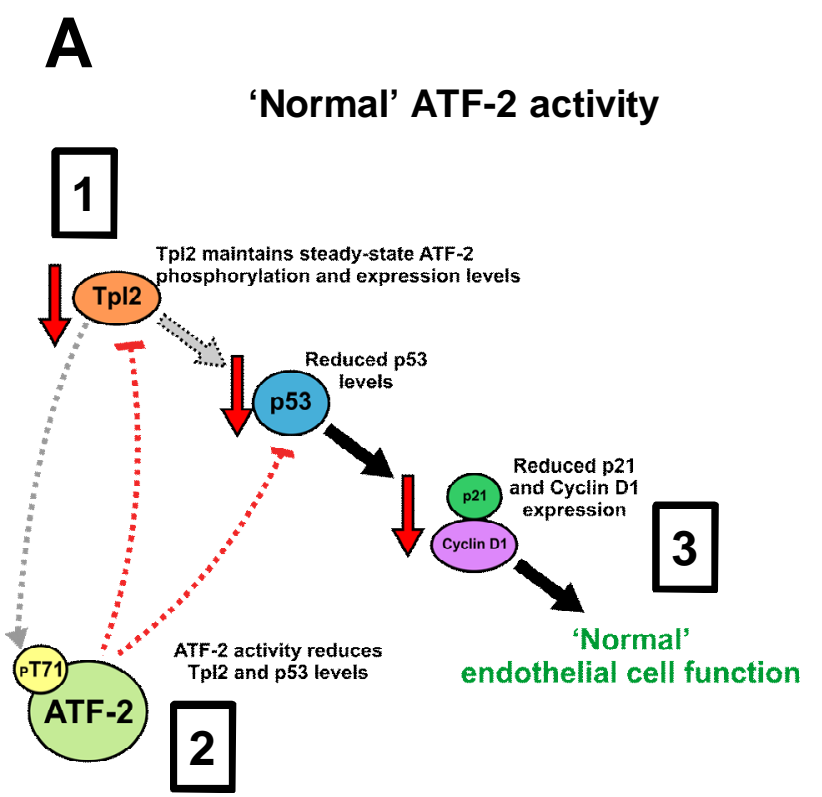

B

\section{Reduced ATF-2 activity}

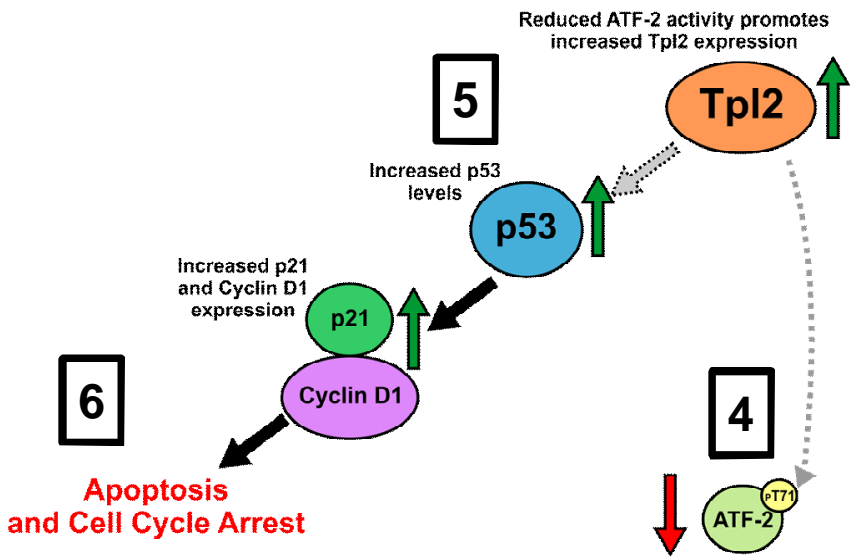

Endothelial cell 
Figure S1

A
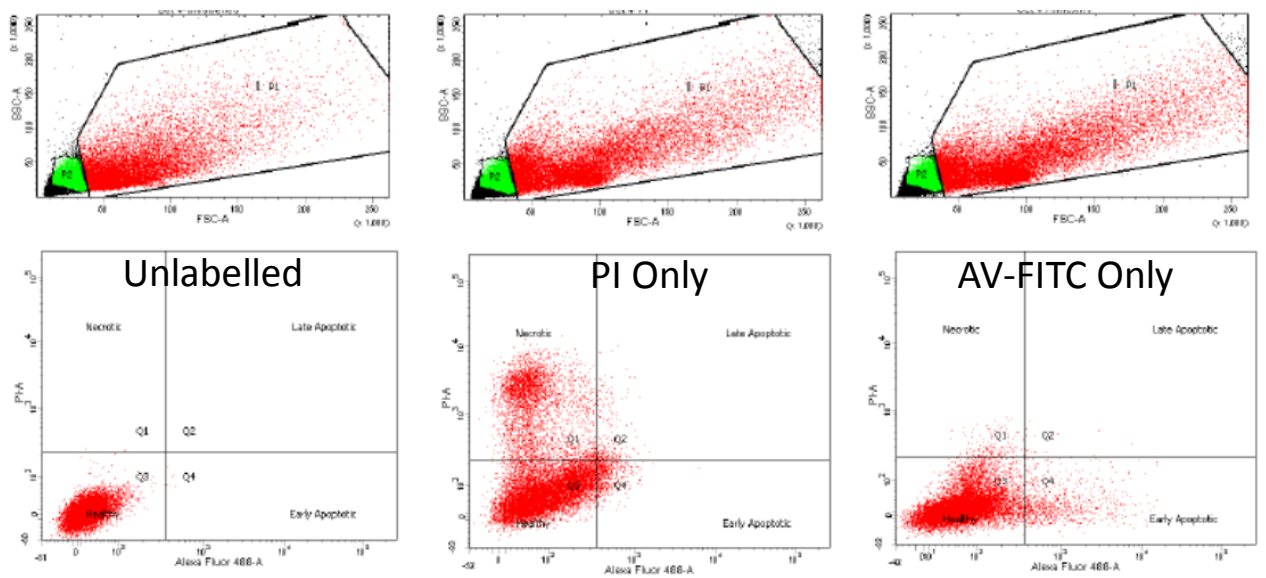

B
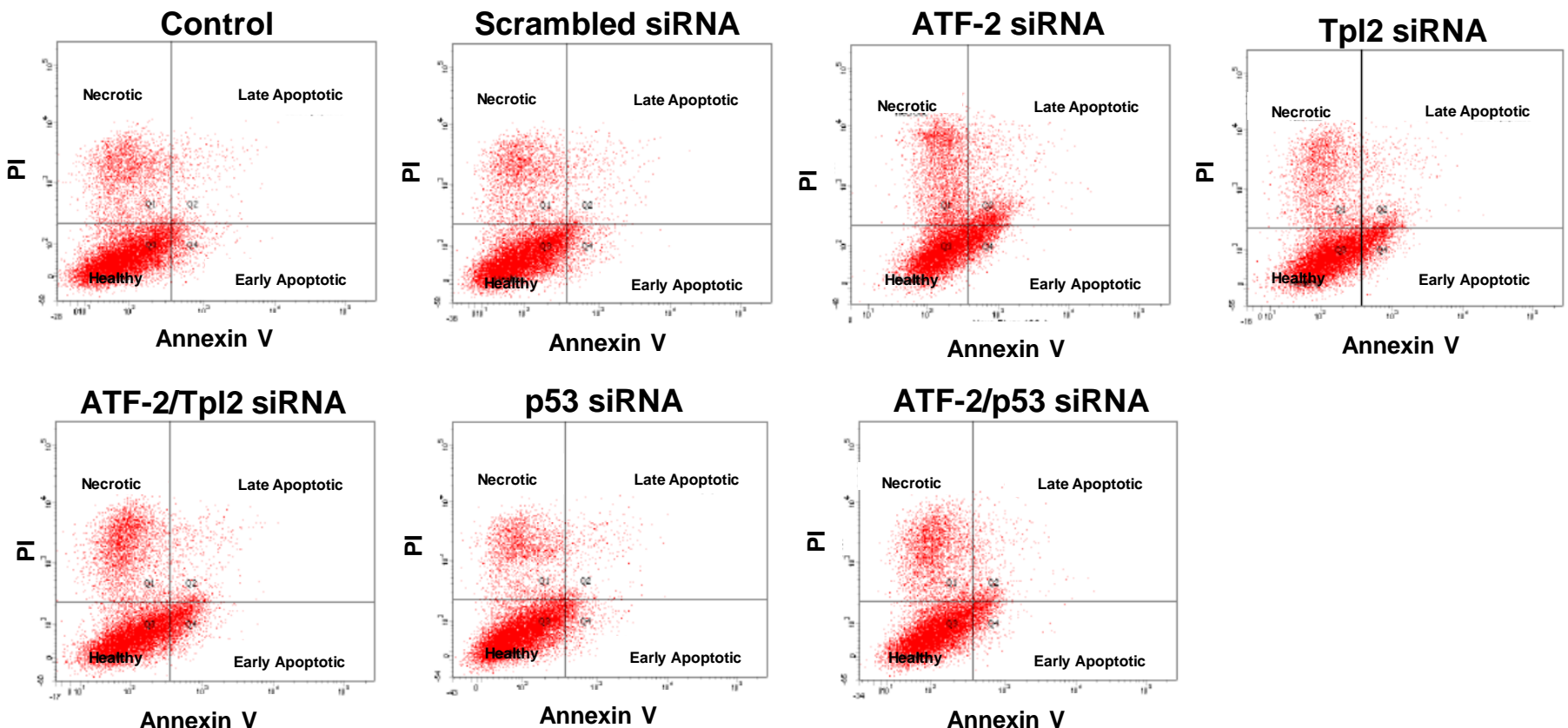

Annexin V

Annexin V

Annexin V

Annexin V

Figure S1. Flow cytometry analysis of endothelial cell apoptosis. (A) Control untreated endothelial cells were subjected to no labelling or with either propidium iodide (PI) or AnnexinVFITV (AV-FITC). (B) Endothelial cells subjected to treatments using scrambled, ATF-2, p53, Tpl2, ATF-2/p53, ATF-2/Tpl2 siRNA duplexes before flow cytometry analysis using combined propidium iodide and Annexin V-FITC staining (see Materials and Methods). The different cell populations (healthy, necrotic, early apoptotic and late apoptotic) are indicated in each quadrant. 